\title{
Low Galanin Serum Levels are Associated with Anxiety in Opioid-Maintained Patients
}

Keywords: Heroin; Diacetylmorphine; Diamorphine; Levomethadone; Galanin; Opioid-maintenance treatment

\begin{abstract}
Aim: To investigate the relationship between the neuropeptide galanin and the clinical effects of diamorphine and levomethadone in opioid-dependent patients.

Methods: We measured serum levels of galanin in opioid dependent patients who received dia(cetyl)morphine (DAM) or (levo-) methadone (POL) in a Swiss (12 DAM) and German sample (55 POL/28 DAM). Behavioral symptoms were measured by psychometric tests (Heroin Craving Questionnaire (HCQ), State-Trait Inventory (STAI), Beck Depression Inventory, 2nd edition (BDI-II) and Symptom Checklist-27 (SCL-27)).

Results: We found significantly decreased galanin serum levels in opioid-dependent patients. The galanin serum levels were significantly lowerin the subgroup of levometha done treated patientscompared to the diamorphine subgroup $(M D=2.65, S D=0.48, p<0.001$ ). Furthemore we found a significant negative association between galanin serum levels and anxiety (STAI-I $(r=0.383, p=0.003)$ STAI-II $(r=0.299, p=0.022)$ ) Galanin seems to be an important target for modulating stress reactions (e.g. craving, anxiety) in opioid-dependent patients.
\end{abstract}

\section{Introduction}

Galanin is a neuropeptide which consists of 30 amino acids in human. It can be found in the central (CNS) and in the peripheral nervous system (PNS) [1]. Its precursor is preprogalanin which is encoded by the GAL gene, located on chromosome 11q13.3-q13.5 and expressed at low levels in about $5 \%$ of dorsal root ganglion (DRG) neurons [2]. There are three more proteins in the galanin family: galanin message-associated protein (GMAP), galanin-like peptide (GALP) and alarin and 3 receptors (GALR1, GALR2, and GALR3) [3]. Galanin shows inhibitory and hyperpolarizing effects and procures neuroprotectivity and neurogenesis $[4,5]$. For example, it plays a trophic role in the DRG following peripheral nerve injury. Furthermore, a lot of data suggests that galanin plays incremental survival roles within neuronal subpopulations of the PNS and CNS $[6,7]$.

Besides a possible connection to somatic disorders like epilepsy [8], obesity [9] and cancer [10], alterations in galanin expression are also thought to impact psychiatric diseases [11]. Zhao et al. discussed the role of the galanin system in modulating depression, anxiety and addiction-like behaviors after chronic restraint stress. They postulated that activating the galanin system, with corresponding changes to noradrenergic systems, following chronic stress may modulate stressassociated behaviors and opiate addiction. The messenger ribonucleic acid (mRNA) levels of galanin, GALR1, and tyrosine hydroxylase were enhanced following stress, suggesting activation of the galanin

\section{Journal of}

Addiction \& Prevention

Adrian Groh ${ }^{1 *}$, Marie Rehme ${ }^{1}$, Rilana Schuster ${ }^{1,2}$, Kenneth Michael Dürsteler-MacFarland ${ }^{3}$, Gerhard Wiesbeck ${ }^{3}$, Marc Walter ${ }^{3}$, Ralf Lichting hagen ${ }^{4}$, Helge Frieling $^{1}$, Stefan Bleich ${ }^{1}$, Thomas Hillemacher ${ }^{1}$ and Annemarie Heberlein ${ }^{1}$

${ }^{1}$ Center for Addiction Research (CARe), Department of Psychiatry, Social Psychiatry and Psychotherapy, Hannover Medical School, Hannover, Germany

${ }^{2}$ Department of Addictive Behavior and Addiction Medicine, Central Institute of Mental Health, Medical Faculty Mannheim/Heidelberg University, Mannheim, Germany

${ }^{3}$ Department of Psychiatry (UPK), University of Basel, Basel, Switzerland

${ }^{4}$ Institute of Clinical Chemistry, Medical School Hannover,

Hannover, Germany

\section{*Address for Correspondence}

Adrian Groh, Centre for Addiction Research (CARe), Department of Psychiatry, Social Psychiatry and Psychotherapy, Hannover Medical School, Carl-Neuberg-Straße 1, 30625 Hannover, Germany, Tel: +49 (0) 511532 7357; Fax: +49 (0) 511532 18569; E-mail: groh.adrian@mh-hannover.de

Submission: 12 January, 2016

Accepted: 01 March, 2016

Published: 05 March, 2016

Copyright: ( $) 2016$ Groh A, et al. This is an open access article distributed under the Creative Commons Attribution License, which permits unrestricted use, distribution, and reproduction in any medium, provided the original work is properly cited.

Reviewed \& Approved by: Dr. Philip Holmes, University of Georgia,

and noradrenergic systems in nucleus accumbens [12].

Another possible explanation for the connection of galanin expression and addiction is the interaction between its expression and dopaminergic transmission. In 1987, Norwegian scientists found galanin and dopamine to coexist in nerve endings, for example in the median eminence of hypothalamus [13]. In vitro experiments revealed that galanin inhibited the release of dopamine in a dose-dependent manner, possibly via a presynaptic receptor [14]. Furthermore, preclinical research results could show that while dopamine transmission is inhibited, galanin and the synthetic galanin receptor agonist gal none reduced cocaine-induced hyperactivity and relapse-like behavior [15]. Also, Picciotto mentioned hypothalamic function to modulate the mesolimbic dopamine system and named galanin receptors to be potential targets for the development of novel treatments for addiction [16].

Another explanation for the connection between galanin expression and addiction may be its impact on the HPA (hypothalamic-pituitary-adrenal axis), also known as the stress-axis. There are study results to suggest that galanin decreases the activity of the HPA through GALR1 receptors in a state-dependent manner under stressful conditions [17]. Furthermore, a correlation between galanin administration and elevated stress-related hormones has been reported [18]. The HPA is known to affect mood and thereby 
impacting affective disorders [19,20]. Moreover, it is considered that alterations in the activity of the HPA are important for understanding the underlying brain mechanisms of substance use disorders [21]. More precisely, changes in the release of the steroid hormone cortisol, which is produced in the adrenal cortex, have been associated with symptoms of substance dependence. Cortisol can interact with the brains reward system which may contribute to dependence causing substance's reinforcing effects. Also it can influence cognitive processes, promoting habit-based learning which can influence habit formation and risk of relapse $[22,23]$.

In 2006, Holmes reviewed the evidence on a potential role for galanin in modulating stress-related neural pathways and behaviors and speculates on the therapeutic potential of targeting this galanin system for opiate addiction. e.g. galanin agonists have been shown to decrease behavioral signs of opiate withdrawal, which are thought to result from hyperactivation of brain stress pathways [24].

Our research group could already show decreased galanin serum levels during acute alcohol withdrawal [25]. In line with a possible interplay between galanin expression and HPA activity, we found a significant negative association between the galanin serum levels and craving measured by the Obsessive Compulsive Drinking Scale (OCDS) in a sample of alcohol-dependent patients.

Summing up our research progress, we could identify neuropeptides like brain-derived neurotrophic factor (BDNF), nerve growth factor (NGF) and galanin as possible bio-markers for substance disorders [25-30].

A variety of substances are used for opioid-maintenance treatment. (Levo-)Methadone, buprenorphine, morphine and diacetylmorphine (DAM) produce favorable treatment retention and outcome in opioid-dependence. Thus, the aim of this study was to investigate a possible connection between the different clinical effects of both opioid maintenance therapies possibly mirrored by alterations in galanin serum levels. In particular, we aimed to find a correlation between galanin serum levels and opiate craving.

\section{Material/Methods}

\section{Patients and design}

The trial was approved by the ethics committees of the Medical School of Hannover and the University of Basel. Opioid-maintained patients, known to the study coordinators from their treatment, were asked for participating. They received written and oral information and gave their informed consent before inclusion. All patients who agreed got a financial compensation.

We examined serum galanin levels from two different samples. One sample was recruited in Hannover, Germany, the other in Basel, Switzerland. Both samples fulfilled the diagnosis of opioid dependence, present participation in a medically monitored drug compensational program (F11.22) according to the International Classification of Diseases and Related Health Problems (ICD-10, 10th Revision).

In the "Hannover Sample" psychometric data in form of the Heroin Craving Questionnaire (HCQ), State-Trait Inventory (STAI) and Beck Depression Inventory, 2nd edition (BDI-II) was collected between administration and blood extraction.

In the "Basel Sample" Heroin Craving Questionnaire and Symptom Checklist-27 (SCL-27) was collected. The psychometric data was collected before (T1) and after (T2) administration and blood extraction.

Participants of the control-group were recruited by notices on a local bulletin board in the region of Hannover. No psychometric data was collected. The group consisted of 51 participants (mean age: 38.62 years; SD: 16.29 ; male/female: $2 / 1$ ) who did not suffer from any psychiatric disease or substance related disorder except smoking. The control-group was age-and gender-matched to the group of the "Sample Hannover".

\section{Diagnostics}

The Heroin Craving Questionnaire (HCQ) is a multidimensional, self-report 45 item-questionnaire designed to assess five theoretically distinct conceptualizations of craving in an adult population: "desire", "intention", "anticipation", "relief" and "lack". It measures opiate craving on a 7-point-Likert scale [31].

The Symptom-Checklist (SCL-27) measures a collection of subjective impairments through physical and mental symptoms. There are six subscales: "depressive", "dysthymic", "vegetative", "agoraphobic", "sociophobic symptoms" and "symptoms of mistrust". The Items are rated on a 5-point-Likert scale, ranging from "not at all" to "extremely" [32].

The State-Trait Anxiety Inventory (STAI) is based upon the discrimination between anxiety as a state (STAI I) and a trait (STAI II). There are two subscales with 20 items each, ranging from "not at all" to "very" [33]

The Beck Depression Inventory, 2nd edition (BDI-II), is a 21-question multiple-choice self-report inventory, measuring the severity of depression, consisting of 21 items ranging 0 to 3 points [34].

\section{(1) The first sample was collected in Hannover, Germany}

There were two subgroups of opioid-maintained patients. One group included 55 opioid-maintained patients with levomethadone (polamidone), directly recruited from the drug scene. The other one consisted of 28 patients receiving intravenous or intramuscularly diamorphine recruited from the Diamorphine Prescription Centre of the Department of Psychiatry, Social Psychiatry and Psychotherapy of the Hannover Medical School. Blood samples were taken between 8:00 a.m and 10:00 a.m, approximately two hours after receiving the morning dose of levomethadone or diamorphine respectively.

\section{(2) The second sample was collected in Basel, Switzerland}

There were twelve intravenous or intramuscularly diamorphinemaintained patients. Two received additional oral diamorphine and three received additional oral methadone. All were recruited from the Diamorphine Prescription Centre of the Psychiatric Hospital of the University of Basel. There were four blood extractions per patient: Two within the morning diamorphine administration and two within the vespertine diamorphine administration, in each case $5 \mathrm{~min}$ before and 5 min after administration. All participants in the Switzerland were all male. 
Citation: Groh A, Rehme M, Schuster R, Michael K, MacFarland D, et al. Low Galanin Serum Levels are Associated with Anxiety in Opioid-Maintained Patients. J Addiction Prevention. 2016;4(1): 7.

\section{Quantification of biomarkers}

After blood withdrawal samples were centrifuged immediately and aliquoted serum samples were stored at $-80^{\circ} \mathrm{C}$ until testing. Galanin was quantified in serum samples with a competitive enzyme linked immunosorbent assay (Cloud-Clone Corp., Houston, USA). According to the manufacturer's instructions $50 \mu \mathrm{l}$ of undiluted serum samples were analyzed per well. The measurement range of the assay was from 12.35 to $1000 \mathrm{ng} / \mathrm{l}$ with a minimum detectable dose of $5 \mathrm{ng} / \mathrm{l}$. The coefficients of variation (precision within an assay) were $<10 \%$ and (precision between assays) $<12 \%$.

\section{Statistical analysis}

All statistical analyses were performed using the Statistical Package for the Social Sciences (SPSSTM) for Windows 22.0 (SPSS Inc., Chicago, IL). Hypothesis of the normal distribution of the galanin serum levels was rejected by means of the KolmogorovSmirnov test. Therefore the galanin serum levels were $\ln$-transformed in order to reach normal distribution. Afterwards, correlations were calculated by Pearson's correlation coefficient. In the "Sample Hannover" the differences in the galanin serum levels of the three groups (diamorphine-, levomethadone- and control-group) were compared applying the analysis of variance with bonferroni post hoc test. Group differences between controls and diamorphine maintained patients in the "Sample Basel" were calculated using independent samples t-tests. Alterations of galanin serum levels preand post-diamorphine treatment in the "Sample Basel" were assessed by the t-test for dependent samples.

In order to measure a possible association between trait anxiety and the galanin serum levels we calculated a cut-off-score according to Grant et al. [35]. Group to group differences in patients suffering from high versus patients not suffering from high trait anxiety were calculated using the independent samples t-test.

Associations between the psychometric dimensions of heroin craving and the galanin serum levels were obtained by Pearson's correlation.

The statistical tests were performed applying a significance level of $\alpha<0.05$.

\section{Results}

\section{Demographic data}

(1) Association between galanin serum levels and dosage of opioid-maintenance treatment

\section{(a) Sample Basel}

We found a significant association between the galanin serum levels and the dosage of diamorphine at T1 $(\mathrm{r}=0.799, \mathrm{p}=0.02)$ and $\mathrm{T} 2(\mathrm{r}=0.771, \mathrm{p}=0.015)$.

There was no similar association regarding methadone-treatment and galanin serum levels.

\section{(b) Sample Hannover}

There was no significant association but a trend towards a significant association between diamorphine-treatment $(\mathrm{r}=0.365, \mathrm{p}=0.056)$ and the galanin serum levels.
(2) Group to group differences (levomethadone vs. diamorphine vs. controls)

\section{(a) Sample Hannover}

The galanin serum levels were significantly different in the three groups $(\mathrm{F}=71.07, \mathrm{p}<0001)$. The galanin serum levels were significantly increased in the diamorphine-maintained patients compared to the levomethadone-maintained patients $(\mathrm{MD}=2.65, \mathrm{SD}=0.48, \mathrm{p}<0.001)$ (Figures 1 and 2$)$. The galanin serum levels of the levomethadone-group were significantly reduced compared to healthy controls $(\mathrm{MD}=-5.79, \mathrm{SD}=0.48$, $\mathrm{p}<0.001)$ as well as compared to the diamorphine-maintained patients ( $\mathrm{MD}=-2.65, \mathrm{SD}=0.48, \mathrm{p}<0.001$ ) (Figures 1 and 2 ).

There were no significant group to group differences regarding affective symptoms of opioid-dependence (measured by the BDI, STAI-I and STAI-II, data not shown).

\section{(b) Sample Basel}

The galanin serum levels were significantly decreased in the patients group compared to the control-group ( $\mathrm{T} 1$ : $\mathrm{t}=-$

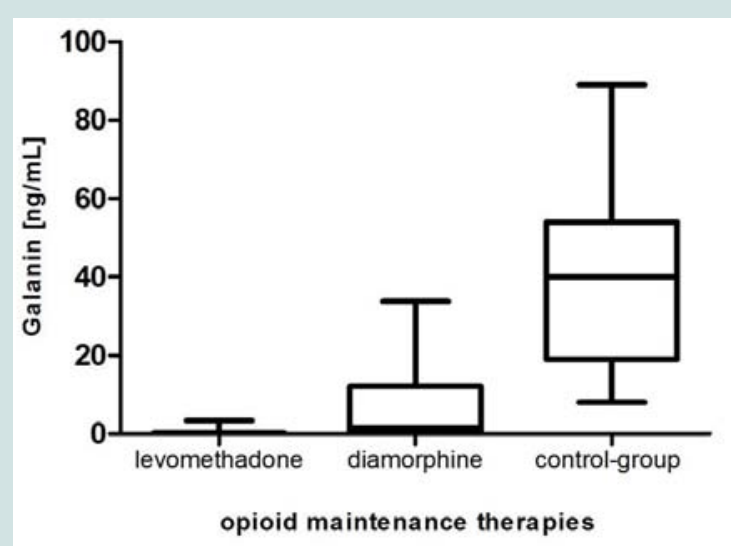

Figure 1: Galanin serum levels in the levomethadone-and the diamorphinesubgroup two hours after receiving the morning dose of their maintenance medication and the control-group.

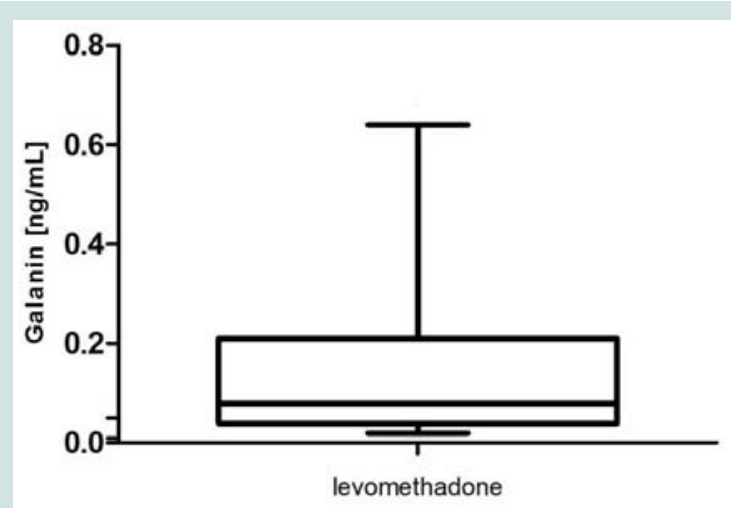

opioid maintenance therapy

Figure 2: Galanin serum level of the levomethadone-subgroup two hours after receiving the morning dose of their maintenance medication in more detail. 


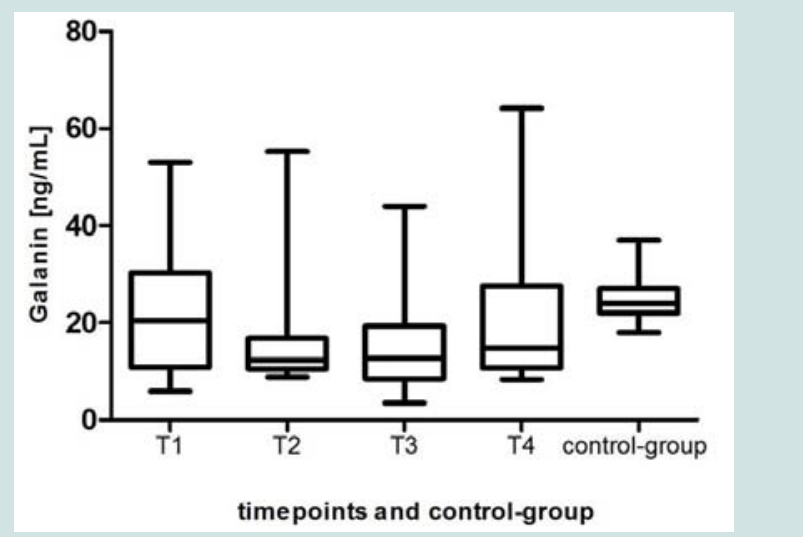

Figure 3: Galanin serum levels in different time points in the "Sample Basel" (i.v./i.m. diamorphine) vs. the control-group.

2.50, $\mathrm{p}=0.015, \mathrm{~T} 2: \mathrm{t}=-2.784, \mathrm{p}=0.007$, T3: n.s., $\mathrm{T} 4: \mathrm{t}=-2.444$, $\mathrm{p}=0.018$ ) (Figure 3 for details). There was no significant alteration between the galanin serum levels pre- and post diamorphine treatment neither in the morning nor in the afternoon (data not shown)

(3) Association between galanin serum levels and opiate craving and opiate withdrawal

\section{(a) Sample Hannover}

There was neither a significant association between the galanin serum levels and the HCQ-score nor its subscales.

\section{(b) Sample Basel}

The galanin serum levels were significantly associated with craving for cocaine $(\mathrm{r}=-0.281, \mathrm{p}=0.031)$ and methadone $(\mathrm{r}=$ $0.317, \mathrm{p}=0.015$ ) on a visual analogue scale.

There was a negative correlation between the total score of the HCQ and the serum levels of galanin after diamorphine application (t2) $(\mathrm{r}=-0.836, \mathrm{p}=0.005)$. Furthermore, following diamorphine application in the morning (t2) there were also negative correlations between the galanin serum levels and the subscales of the HCQ: anticipation $(\mathrm{r}=-0,768 \mathrm{p}=0.016)$, relief $(\mathrm{r}=-0.830, \mathrm{p}=0.006)$ and lack of heroin $(r=-0,668, p=0.049)$.

\section{(4) Association between the galanin serum levels and anxiety}

\section{(a) Sample Hannover}

The galanin serum levels were significantly associated with trait anxiety measured by the STAI-II score in the group of the diamorphine-maintained patients $(\mathrm{r}=-0.473, \mathrm{p}=0.013)$. No association between the STAI-II score and the galanin serum levels was observed in the levomethadone-maintained patients.

In the whole patients group (diamorphine- and levomethadonemaintained patients), the galanin serum levels were significantly associated with the BDI score $(\mathrm{r}=-0.393, \mathrm{p}=0.002)$, the STAI-I score $(\mathrm{r}=-0.383, \mathrm{p}=0.003)$ and the STAI-II score $(\mathrm{r}=-0.299, \mathrm{p}=0.022)$ in those patients who suffer from high trait anxiety levels (49 patients, measured by a cut-off score $>40$ points in the STAI-II according to [35] ).
Moreover, the galanin serum levels were significantly higher in those patients who did not reach (9 patients compared to 49 patients) the cut-off-score according to Grant et al. $(\mathrm{t}=-0.264, \mathrm{p}=0.011)$.

\section{(b) Sample Basel}

In the "Sample Basel" there was a positive correlation between the item "Being afraid in public places" at T3 $(r=0.850, p=0.004)$ and "A lump in your throat" with $\mathrm{T} 1(\mathrm{r}=0.478, \mathrm{p}=0.049)$ and $\mathrm{T} 3(\mathrm{r}=0.759$, $\mathrm{p}=0.018$ ) of the SCL-27.

(5) Group to group differences of HCQ-Scores (levomethadone vs. diamorphine)

\section{(a) Sample Hannover}

There was a tendency towards higher scores of the HCQ sum-score regarding in the levomethadone $(\mathrm{MD}=152.98, \mathrm{SD}=65.10)$ compared with the diamorphine-maintained $(\mathrm{MD}=129.43, \mathrm{SD}=51.62)$ patients. A significant group to group difference was found regarding the subscale intention to use heroin torwards levomethadone $(t=-2.054$, $\mathrm{p}=0.043)$.

\section{Discussion}

The aim of the present study was to investigate a possible association between the clinical effects of diamorphine and levomethadone in opioid-dependent patients and the serum expression of the neuropeptide galanin.

The major finding of the study was the significant difference of the serum levels of galanin in the diamorphine-maintained patients compared to the levomethadone-subgroup in the "Sample Hannover": The galanin serum levels were significantly decreased in both groups of opioid-maintained patients compared to the healthy control-group (see Figures 1 and 2). We also found significantly increased galanin serum levels in the diamorphine-maintained patients compared with the levomethadone patients.

However there was no direct effect of diamorphine treatment on the galanin serum levels in the "Sample Basel". It could be that possible alterations in galanin serum expression due to opioid-maintenance treatment may be long term rather than acute. We observed a positive association between diamorphine dosages and the galanin serum expression which may point towards a possible substitution effect of diamorphine. Vice versa decreased galanin serum levels may be a possible biological marker mirroring the severity of opioiddependence regarding our results of a possible connection between trait and state anxiety and the galanin serum levels. Here, we found a negative association of the galanin serum levels and anxiety in both samples (measured in Hannover by the STAI-I and II and the item 18 of the SCL 27 ("a lump in the throat") in "Sample Basel") as well as a significant group to group difference regarding patients suffering from high anxiety versus patients not-suffering from trait anxiety. This result implies that galanin serum levels may mirror affective symptoms of opioid-dependence which in turn react to opioidmaintenance treatment. Consistent with such hypotheses, the galanin serum levels were significantly decreased in patients suffering from high trait anxiety compared to their healthy participants. Moreover, in line with a possible association between the severity of the affective syndrome of opioid-dependence and the galanin serum expression, 
Citation: Groh A, Rehme M, Schuster R, Michael K, MacFarland D, et al. Low Galanin Serum Levels are Associated with Anxiety in Opioid-Maintained Patients. J Addiction Prevention. 2016;4(1): 7.

ISSN: $2330-2178$

Table 1: Sample Basel $(n=12)$.

\begin{tabular}{|c|c|c|c|c|}
\hline & \multicolumn{4}{|c|}{ Diamorphine i.v.li.m. } \\
\hline & Min & $\operatorname{Max}$ & Mean value & Standard deviation \\
\hline Age & 32 & 52 & 43.25 & 5.413 \\
\hline Age of onset & 14 & 26 & 18.92 & 4.52 \\
\hline Dose of diamorphine i.v./i.m. (mg) & 180 & 600 & 343.33 & 133.23 \\
\hline Galanin serum level (ng/l) & 5.90 & 53 & 22.58 & 14.40 \\
\hline Parallel consumption of other drugs last 7 days $(y / n)$ & 1 & 2 & 1.17 & 0.39 \\
\hline Heroin last 7 days $(\mathrm{y} / \mathrm{n})$ & 1 & 2 & 1.92 & 0.29 \\
\hline Cocaine last 7 days $(y / n)$ & 1 & 2 & 1.5 & 0.52 \\
\hline Benzodiazepine last 7 days $(y / n)$ & 1 & 2 & 1.75 & 0.45 \\
\hline THC last 7 days $(y / n)$ & 1 & 2 & 1.5 & 0.52 \\
\hline SCL-27-item 18 & 0 & 2 & 0.42 & 0.669 \\
\hline SCL-27-score & 4 & 62 & 18.83 & 16.36 \\
\hline HCQ-desire & 24 & 62 & 47.50 & 10.31 \\
\hline HCQ-intention & 19 & 63 & 47.33 & 12.22 \\
\hline HCQ-anticipation & 16 & 61 & 47.33 & 12.22 \\
\hline HCQ-relief & 25 & 50 & 42.42 & 7.28 \\
\hline HCQ-lack & 35 & 62 & 46.42 & 8.01 \\
\hline HCQ-score & 134 & 293 & 231.00 & 41.54 \\
\hline
\end{tabular}

Table 2: Sample Hannover $(n=55)$

\begin{tabular}{|c|c|c|c|c|}
\hline & \multicolumn{2}{|c|}{ Diamorphinei.v.li.m. } & \multicolumn{2}{|c|}{ Levomethadone oral } \\
\hline & Mean value & Standard deviation & Mean value & Standard deviation \\
\hline Age & 41.68 & 7.912 & 37.59 & 7.51 \\
\hline Gender & 1.14 & 0.356 & 1.37 & 0.457 \\
\hline BMI (Body-Mass-Index) & 25.86 & 5.04 & 23.81 & 3.99 \\
\hline Age of onset & 18.21 & 4.05 & 18.89 & 12.52 \\
\hline Dose ofdiamorphine (mg) & 657.32 & 265.45 & - & - \\
\hline Dose of levomethadone (mg) & - & - & 44.58 & 20.50 \\
\hline Galanin serum level (ng/l) & 7.477 & 10.96 & 0.19 & 0.62 \\
\hline $\begin{array}{l}\text { Parallel consumption of other drugs last } 7 \\
\text { days }(y / n)\end{array}$ & 1 & 0 & 1.04 & 0.19 \\
\hline Heroin last 7 days $(y / n)$ & 1 & 0 & 1.44 & 0.50 \\
\hline THC last 7 days & 1.07 & 0.27 & 1.50 & 0.50 \\
\hline BDI-score & 21.32 & 10.42 & 22.26 & 11.16 \\
\hline STAI I-score & 46.86 & 10.90 & 50.54 & 12.06 \\
\hline STAI II-score & 49.79 & 10.41 & 51.11 & 10.88 \\
\hline HCQ-score & 129.43 & 51.82 & $152, .98$ & 65.10 \\
\hline HCQ-desire & 20.35 & 11.36 & 26.40 & 16.06 \\
\hline HCQ-intention & 22.39 & 11.38 & 28.81 & 14.25 \\
\hline HCQ-anticipation & 26.14 & 11.97 & 30.94 & 14.21 \\
\hline HCQ-relief & 30.43 & 11.05 & 32.73 & 11.88 \\
\hline HCQ-lack & 30.11 & 12.81 & 34.08 & 13.78 \\
\hline
\end{tabular}


we observed a negative correlation of galanin serum expression and craving for opiates, measured by the HCQ following diamorphine application in the "Sample Basel". More precise, we observed a negative correlation of galanin serum expression and the subscales "anticipation of heroin effects" ( $\mathrm{r}=-0,768 \mathrm{p}=0.016)$ and "relief" due to heroin application $(r=-0.830, p=0.006)$.It could be hypothesized that a disturbance in the galanin expression due to opioid-dependence may reduce affective symptoms. Supporting such hypotheses, we found no dynamic in the galanin serum levels due to diamorphine application. However, there was no significant group difference regarding the BDI, STAI-I or the STAI-II scores between the diamorphine- and the levomethadone-maintained patients.

As mentioned before, there may be a connection to the HPAaxis: Opioid-dependent patients display high levels of craving and stress, organizing life around purchase and consumption of the drug [36]. In the early 90s, a polish research group speculated about a possible involvement of galanin in the modulation of the function of pituitary-adrenocortical axis under basal and stressful conditions [18]. Therefore galanin was injected s.c.in a rat model, which resulted in a marked rise in the blood levels of adrenocorticotropic hormone $(\mathrm{ACTH})$, aldosterone and corticosterone.

Galanin may have a role in the process of stress adaptation in the noradrenergic system, as expression of preprogalanin mRNA in the locus coeruleus is increased in response to chronic social stress [37].

Regarding the expression of galanin in the central amygdala, a brain region involved in stress- and anxiety-related behaviors, a connection between anxiety/stress and galanin-expression seems to be highly probable, although there are no supporting results from clinical and preclinical until today [38].

\section{Limitations}

Although being of high validity, future studies should match sample sizes relatively to the small number of subjects and the parallel consumption of other drugs of the opioid-maintained patients. The consumption of street heroin, cocaine, cannabinoids (THC) and benzodiazepines within the last seven days was documented (see Tables 1 and 2).

The serum level of galanin may also be influenced by the dosage of the maintenance therapy which ranges in both samples. e.g. the mean dosage of diamorphine being twice as high in the German as in the Swiss sample (see Tables 1 and 2). Furthermore it may be correlated with the duration of the maintenance therapy which data wasn't available for all patients.

Also, we did not measure the activity of the HPA in form of stress hormones (ACTH, corticosteroids etc.) to confirm our hypothesis of a possible association between craving, galanin expression and HPA activity. Galanin is known to play an important role in appetite control [39]. So it might be a limitation that the participants were not on an empty stomach.

\section{Conclusion}

Summing up, we found a decrease of galanin serum levels in opioid-maintained patients (see Figure 1). Concretely we found significantly decreased galanin serum levels in opioid-dependent patients and a more pronounced decrease in the subgroup of levomethadone-maintained patients compared to the diamorphinesubgroup.

As galanin serum levels were significantly associated with opiate craving measured by the HCQ, the decrease of galanin serum levels found in the opioid-dependent patients may mirror a neurobiological mechanism of opiate craving. According to such hypotheses HCQscores were significantly increased in levomethadone-subgroup compared to the diamorphine-subgroup. In-line with such associations we also found a significant association between galanin serum levels and anxiety, which may be explained by a possible interaction between HPA activity and galanin expression as reported in preclinical studies [18]. Regarding the various limitations of our study, our results have to be confirmed by greater samples of opioiddependent patients.

\section{References}

1. Vrontakis ME (2002) Galanin: a biologically active peptide. Curr Drug Targets CNS Neurol Disord 1: 531-541.

2. Evans H, Baumgartner M, Shine J, Herzog H (1993) Genomic organization and localization of the gene encoding human preprogalanin. Genomics 18 : 473-477.

3. Lang R, Gundlach AL, Kofler B (2007) The galanin peptide family: receptor pharmacology, pleiotropic biological actions, and implications in health and disease. Pharmacol Ther 115: 177-207.

4. Lang R, Gundlach AL, Holmes FE, Hobson SA, Wynick D, et al. (2015) Physiology, signaling, and pharmacology of galanin peptides and receptors: three decades of emerging diversity. Pharmacol Rev 67: 118-175.

5. Mitsukawa K, Lu X, Bartfai T (2010) Galanin, galanin receptors, and drug targets. EXS 102: 7-23.

6. Ji RR, Zhang X, Zhang Q, Dagerlind A, Nilsson S, et al. (1995) Central and peripheral expression of galanin in response to inflammation. Neuroscience 68: 563-576.

7. Hobson SA, Bacon A, Elliot-Hunt CR, Holmes FE, Kerr NC, et al. (2008) Galanin acts as a trophic factor to the central and peripheral nervous systems. Cell Mol Life Sci 65: 1806-1812.

8. Kovac S, Walker MC (2013) Neuropeptides in epilepsy. Neuropeptides 47 467-475.

9. Boughton CK, Murphy KG (2013) Can neuropeptides treat obesity? A review of neuropeptides and their potential role in the treatment of obesity. $\mathrm{Br} \mathrm{J}$ Pharmacol 170: 1333-1348.

10. Nagayoshi K, Ueki T, Tashiro K, Mizuuchi Y, Manabe T, et al. (2015) Galanin plays an important role in cancer invasiveness and is associated with poor prognosis in stage II colorectal cancer. Oncol Rep 33: 539-546.

11. Richardson TG, Minica C, Heron J, Tavare J, MacKenzie A, et al. (2014) Evaluating the role of a galanin enhancer genotype on a range of metabolic, depressive and addictive phenotypes. Am J Med Genet B Neuropsychiatr Genet 165B: 654-664.

12. Zhao X, Seese RR, Yun K, Peng T, Wang Z (2013) The role of galanin system in modulating depression, anxiety, and addiction-like behaviors after chronic restraint stress. Neuroscience 246: 82-93.

13. Wodowska J, Ciosek J (2015) Galanin-like peptide (GALP): localization, receptors and biological function. Postepy Hig Med Dosw (Online) 69: $1067-$ 1076.

14. Nordstrom O, Melander T, Hokfelt T, Bartfai T, Goldstein M (1987) Evidence for an inhibitory effect of the peptide galanin on dopamine release from the rat median eminence. Neuroscience Lett 73: 21-26. 
Citation: Groh A, Rehme M, Schuster R, Michael K, MacFarland D, et al. Low Galanin Serum Levels are Associated with Anxiety in Opioid-Maintained Patients. J Addiction Prevention. 2016;4(1): 7.

15. Ogbonmwan YE, Sciolino NR, Groves-Chapman JL, Freeman KG, Schroede JP, et al. (2015) The galanin receptor agonist, galnon, attenuates cocaineinduced reinstatement and dopamine overflow in the frontal cortex. Addict Biol 20: 701-713.

16. Picciotto MR (2010) Galanin and addiction. EXS 102: 195-208.

17. Picciotto MR, Brabant C, Einstein EB, Kamens HM, Neugebauer NM (2010) Effects of galanin on monoaminergic systems and HPA axis: Potential mechanisms underlying the effects of galanin on addiction- and stress-related behaviors. Brain Res 1314: 206-218.

18. Malendowicz LK, Nussdorfer GG, Nowak KW, Mazzocchi G (1994) The possible involvement of galanin in the modulation of the function of rat pituitary-adrenocortical axis under basal and stressful conditions. Endocr Res 20: 307-317

19. Colich NL, Kircanski K, Foland-Ross LC, Gotlib IH (2015) HPA-axis reactivity interacts with stage of pubertal development to predict the onset of depression. Psychoneuroendocrinology 55: 94-101.

20. Du X, Pang TY (2015) Is dysregulation of the HPA-axis a core pathophysiology mediating co-morbid depression in neurodegenerative diseases? Fron Psychiatry 6: 32 .

21. Stephens MA, Wand G (2012) Stress and the HPA axis: role of glucocorticoids in alcohol dependence. Alcohol Res 34: 468-483.

22. Pierce RC, Kumaresan V (2006) The mesolimbic dopamine system: the final common pathway for the reinforcing effect of drugs of abuse? Neurosc Biobehav Rev 30: 215-238

23. Piazza PV, Le Moal M (1997) Glucocorticoids as a biological substrate of reward: physiological and pathophysiological implications. Brain Res Brain Res Rev 25: 359-372.

24. Holmes A, Picciotto MR (2006) Galanin: a novel therapeutic target for depression, anxiety disorders and drug addiction? CNS Neurol Disord Drug Targets 5: 225-232

25. Heberlein A, Muschler M, Frieling H, Lenz B, Wilhelm J, et al. (2011) Decreased galanin serum levels are associated with alcohol-craving during withdrawal. Prog Neuropsychopharmacol Biol Psychiatry 35: 568-572.

26. Heberlein A, Bleich S, Bayerlein K, Frieling H, Groschl M, et al. (2008) NGF plasma levels increase due to alcohol intoxication and decrease during withdrawal. Psychoneuroendocrinology 33: 999-1003.

27. Heberlein A, Lenz B, Muschler M, Frieling H, Buechl R, et al. (2010) BDNF plasma levels decrease during benzodiazepine withdrawal in patients suffering from comorbidity of depressive disorder and benzodiazepine dependence. Psychopharmacology (Berl) 209: 213-215

28. Heberlein A, Muschler M, Wilhelm J, Frieling $H$, Lenz B, et al. (2010) BDNF and GDNF serum levels in alcohol-dependent patients during withdrawal. Prog Neuropsychopharmacol Biol Psychiatry 34: 1060-1064.

29. Heberlein A, Dursteler-MacFarland KM, Lenz B, Frieling H, Grosch M, et al. (2011) Serum levels of BDNF are associated with craving in opiatedependent patients. J Psychopharmacol 25: 1480-1484.

30. Heberlein A, Dursteler-MacFarland KM, Frieling H, Groschl M, Lenz B, et al. (2012) Association of nerve growth factor and vascular endothelial growth factor $A$ with psychometric measurements of opiate dependence: results of a pilot study in patients participating in a structured diamorphine maintenance program. Eur Addict Res 18: 213-219.

31. Tiffany ST, Haertzen CA, Henningfield J (1993) The development of a heroin question questionnaire. [unpublished manuscript] Purdue University.

32. Hardt J, Egle UT, Kappis B, Hessel A, Brahler E (2004) Symptom Checklist SCL-27. Psychother Psychosom Med Psychol 54: 214-223.

33. Kendall PC, Finch AJ Jr, Auerbach SM, Hooke JF, Mikulka PJ (1976) The State-Trait Anxiety Inventory: a systematic evaluation. J Consult Clin Psychol 44: 406-412.

34. Buckley TC, Parker JD, Heggie J (2001) A psychometric evaluation of the BDI-II in treatment-seeking substance abusers. J Subst Abuse Treat 20: $197-$ 204.

35. Grant KA, McMahon C, Austin MP (2008) Maternal anxiety during the transition to parenthood: a prospective study. J Affect Disord 108: 101-111.

36. Schmidt A, Borgwardt S, Gerber H, Wiesbeck GA, Schmid O, et al. (2014) Acute effects of heroin on negative emotional processing: relation of amygdala activity and stress-related responses. Biol Psychiatry 76: 289-296.

37. Khoshbouei H, Cecchi M, Dove S, Javors M, Morilak DA (2002) Behaviora reactivity to stress: amplification of stress-induced noradrenergic activation elicits a galanin-mediated anxiolytic effect in central amygdala. Pharmacol Biochem Behav 71: 407-417.

38. Bajo M, Roberto M, Madamba SG, Siggins GR (2011) Neuroadaptation of GABAergic transmission in the central amygdala during chronic morphine treatment. Addict Biol 16: 551-564.

39. Fang P, Yu M, Guo L, Bo P, Zhang Z, et al. (2012) Galanin and its receptors: a novel strategy for appetite control and obesity therapy. Peptides 36: 331 339

\section{Acknowledgements}

We thank all patients, volunteers and supporters. We also like to thank technical assistant Bernadette Lüns for performing the laboratory analyses and Laura Schares, M.Sc. for proof reading the article. 